\title{
Primary ovarian carcinoid: a case report
}

\author{
Jameen Kaur $^{1 *}$, Bharti Goel ${ }^{1}$, Alka Sehgal ${ }^{1}$, Vidhu Jaswal ${ }^{2}$
}

${ }^{1}$ Department of Obstetrics \& Gynaecology, GMCH, Chandigarh

${ }^{2}$ Department of Pathology, GMCH, PGI Chandigarh

Received: 27 August 2015

Revised: 07 September 2015

Accepted: 09 September 2015

\section{*Correspondence:}

Dr. Jasmeen Kaur,

E-mail: drjasmeen81@gmail.com

Copyright: (C) the author(s), publisher and licensee Medip Academy. This is an open-access article distributed under the terms of the Creative Commons Attribution Non-Commercial License, which permits unrestricted non-commercial use, distribution, and reproduction in any medium, provided the original work is properly cited.

\section{ABSTRACT}

Primary ovarian carcinoid tumor is a rare entity, usually seen in perimenopausal or menopausal age group, it's rarely malignant. A case study of a $53 \mathrm{yr}$ old female who presented with a large primary ovarian carcinoid is being reported here.

Keywords: Primary stumal carcinoid ovary, Rare ovarian tumors, Primary ovarian tumors.

\section{CASE REPORT}

53 year old, postmenopausal female, $\mathrm{P}_{3} \mathrm{~L}_{3}$ came with complaint of mass abdomen since 5 months. There were no complaints of postmenopausal bleeding, pain abdomen, weight loss, fatigue, weakness or tuberculosis; no bowel or bladder complaints. She had past history of carcinoma of right breast, for which she got operated and received chemotherapy for 8 months in 2005 followed by treatment with Tamoxifen, which had been discontinued for the past one year.

On examination she had an abdomino-pelvic mass of 16 18 week gravid uterus size which was firm, mobile and non-tender. On per speculum and per vaginal examination the same mass could be felt through the right fornix separate from the normal-sized uterus.

Routine investigations were normal. CA-125 was 739 $\mathrm{IU} / \mathrm{ml}$. On ultrasonography, a large pelvic mass $16 \mathrm{~cm} \mathrm{x}$ $15 \mathrm{~cm} \times 10.3 \mathrm{~cm}$, mainly solid with cystic areas was noted adjacent to the uterus. Mild pelvis ascites was seen. No significantly enlarged lymph nodes were noted. Impression-Krukenburg metastasis. On CT, features suggestive of large lobulated, heterogeneous, pelvic abdominal mass 15 by 12 by $10 \mathrm{~cm}$ not seen separately from right ovary. Fat planes with bladder and bowel were indistinct at places suggestive of adhesions or invasion. Uterus showed a deep indentation near fundus, suggestive of bicornuate uterus double uterine cavity. No omental or peritoneal deposits were seen. Streak of free fluid was seen.

On laparotomy, $\sim 100 \mathrm{cc}$ of peritoneal fluid was drained. A large lobulated mass $10 \mathrm{~cm}$ x $15 \mathrm{~cm}$ with intact surface was seen arising from right adnexa. Duplication of uterus and cervix was identified with dense adhesions between bowel and bladder in the intervening space. Left adnexa were normal. Total abdominal hysterectomy with bilateral salpingo oophrectomy with infracolic omentectomy was done.

On histopathology, the predominant component was carcinoid with traberculae, ribbon and nests like arrangement separated by fibrovascular septae. Tumor cells were mildly pleomorphic with round to oval nuclei, stippled chromatin and scanty to moderate cytoplasm. The lesser component showed thyroid follicular cells arranged in variable sized follicles filled with colloid representing the strumal component. Sections of 
omentum were free of tumor. Cervix showed non-specific cervicitis. No other teratomatous component was identified. On immunohistochemistry (IHC), carcinoid component was weak diffuse positive for Synaptophysin and negative for Chromogrannin, Cytokeratin and Inhibin. The strumal component showed nuclear positivity for Thyroid Transcription Factor-1 (TTF-1). IHC confirmed the diagnosis of Strumal Carcinoid.

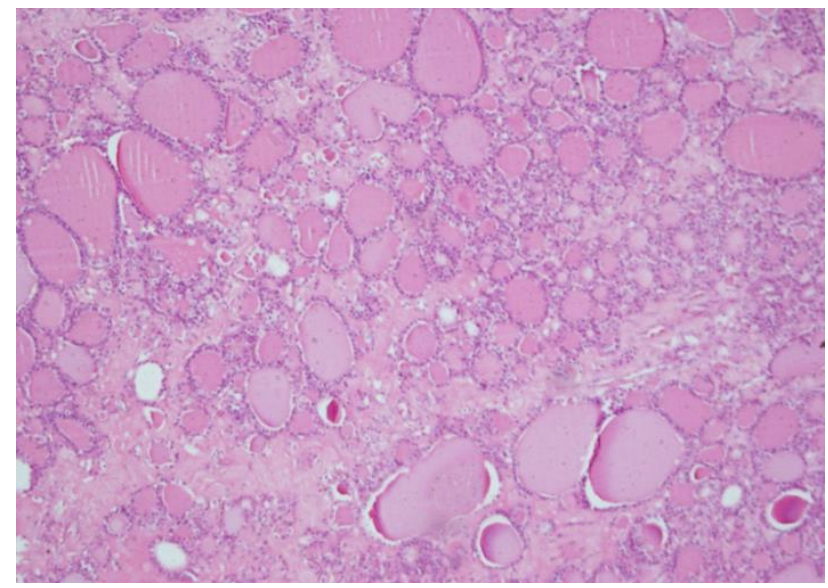

Figure 1: Colloid filled Thyroid follicles in ovarian parenchyma, H\&E X100.

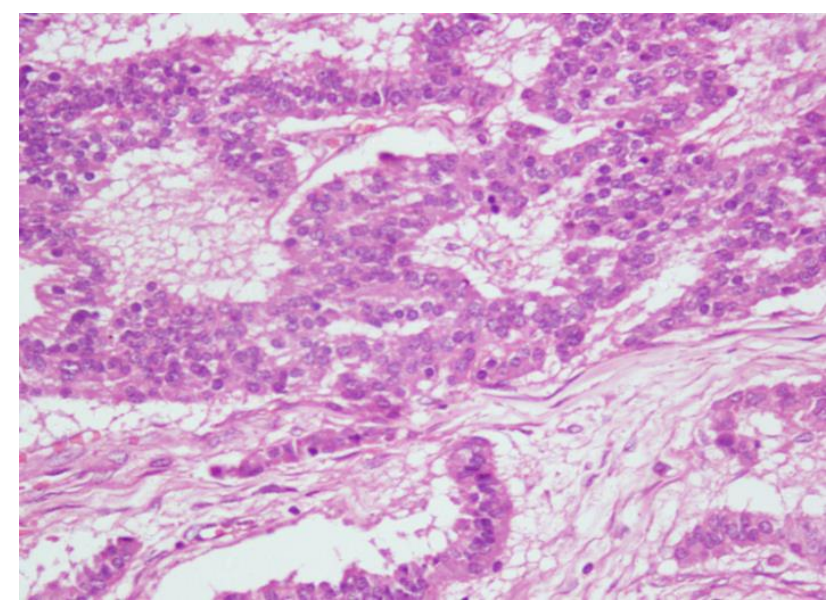

Figure 2: Tumor cells having round uniform nuclei with granular chromatin and abundant eosinophilic cytoplasm, H\&E X400.

\section{Review of literature}

Primary ovarian carcinoid tumors are very rare and are rarely malignant $(<2 \%)$, they account for less than $0.1 \%$ of all ovarian carcinomas and $0.5 \%$ of all carcinoid tumors. They are predominantly seen in perimenopausal and postmenopausal women. ${ }^{1,2}$

Histologically they have been classified as; insular, trabecular, strumal and mucinous. Insular being the most common and comprises of cells in an insular pattern, seen in midgut derived carcinoids, followed by strumal sub type which is a mixture of trabecular carcinoid and thyroid tissue and trabercular pattern. ${ }^{3-5}$ Usually these tumors exhibit features of a singular subtype, but tumors with mixed histological features do exist. ${ }^{6}$

Patients with carcinoid tumors may or may not be symptomatic. Symptoms, if present, may include pressure or pain with defecation and carcinoid syndrome. Carcinoid syndrome is a symptom complex that presents with paroxysmal vasomotor disturbances that occur because of the vasoactive mediators (serotonin, bradykinin, histamine) released by the tumor. Symptoms include on and off abdominal pain, flushing of the face, neck, or upper chest, diarrhoea, palpitations, low blood pressure, telangiectasis and chest wheeze. It causes Cardiac valvular lesions (tricuspid incompetence and pulmonary stenosis) because of plaque-like deposits on the fibrous tissue. Presence of the carcinoid syndrome is dependent on the size of the tumor rather than extent of spread or metastasis. ${ }^{7}$ In one large study, one-half of tumors with a maximal diameter of $4-7 \mathrm{~cm}$ and twothirds of tumors with a maximal diameter of more than 7 $\mathrm{cm}$ were associated with carcinoid syndrome. ${ }^{7}$ Treatment for carcinoid syndrome in such cases is resection of the primary tumor. The insular subtype is the only one which is associated with the carcinoid syndrome and that also is seen in one third of the cases. Strumal carcinoids have been associated with virilism as well as postoperative thyroid storms and hypothyroidism. ${ }^{8-10}$

On imaging, ovarian carcinoid tumors appear as solid hyper vascular masses and are indistinguishable from other solid neoplasms. Presence of a solid hyper vascular ovarian mass in a patient with clinical manifestations of carcinoid syndrome should arouse the suspicion of an ovarian carcinoid tumor.

It is difficult to distinguish between primary ovarian carcinoid and the carcinoid secondary's in the ovary. Unilateral ovarian involvement, the presence of a dermoid cyst and the absence of carcinoid elsewhere are suggestive of primary ovarian origin. ${ }^{11}$ Primary ovarian carcinoids rarely spread beyond the ovary, but metastases to the ovary are almost always accompanied by the presence of metastases elsewhere, especially on the peritoneum and in the liver.

Test for 24 hour urinary 5-hydroxyindoleacetic acid (5HIAA), which is a biodegradation product of serotonin, can be done in the postoperative period or even later. It becomes negative after the removal of a primary ovarian carcinoid but would be positive in cases of metastasis.

Treatment for stage I strumal carcinoid tumors is surgical excision i.e. unilateral or bilateral salpingooophorectomy, with or without hysterectomy

Malignant spread or recurrence after resection is rare, only two of 48 cases of insular ovarian carcinoid developing a recurrence following resection of a tumor have been reported and that too confined to the ovary. ${ }^{10}$ 
The long-term prognosis is favourable. Metastatic disease seems to be limited to the carcinoid or thyroid element, no reports of dual metastases were found. For metastatic thyroid component consider treatment with thyroidectomy and 131I ablation. (Similar to the treatment of metastatic Struma ovary) A single report of the metastatic carcinoid component has been published and that was unsuccessfully treated with ThioTEPA. ${ }^{9,12}$

Funding: No funding sources

Conflict of interest: None declared

Ethical approval: Not required

\section{REFERENCES}

1. Somak R, Shramana M, Vijay S, Nita K. Primary carcinoid tumor of the ovary: a case report. Arch Gynecol Obstet. 2008;277(1):79-82.

2. Modlin IM, Sandor A. An analysis of 8305 cases of carcinoid tumors. Cancer. 1997;79(4):813-29.

3. Kim SM, Choi HS, Byun JS et al. Mucinousadenocarcinoma and strumal carcinoid tumor arising in one mature cystic teratoma of the ovary with synchronous cervical cancer. Journal of Obstetrics and Gynaecology Research. 2003;29(1):28-32.

4. Hart WR. Mucinous tumors of the ovary: a review. International Journal of Gynecological Pathology. 2005;24(1):4-25.
5. DeSimone CP, Lele SM, Modesitt SC. Malignant struma ovarii: a case report and analysis of cases reported in the literature with focus on survival and I131 therapy. Gynecologic Oncology. 2003;89(3):543-8.

6. Davis KP, Hartmann LK, Keeney GL, Shapiro H. "Primary ovarian carcinoid tumors". Gynecologic Oncology. 1996;61(2):259-65.

7. Robboy SJ, Norris HJ, Scully RE. Insular carcinoid primary in the ovary. Cancer. 1975;36:404-18.

8. Talerman A. Carcinoid tumors of the ovary. Journal of Cancer Research and ClinicalOncology. 1984;107(2):125-35.

9. Gorin I, Sastre-Garau X. Strumal carcinoid tumor of the ovary. Journal of Clinical Oncology. 2008;26(16):2780-1.

10. Robboy SJ, Scully RE. Strumal carcinoid of the ovary: an analysis of 50 cases of a distinctive tumor composed of thyroid tissue and carcinoid. Cancer. 1980;46(9):2019-34.

11. Robboy SJ, Scully RE, Nonis HJ. Carcinoid metastatic to the ovary-a clinico-pathologic analysis of 35 cases. Cancer. 1974;33:798-811

12. Armes JE. A case of malignant strumal carcinoid. Gynecologic Oncology, 1993;51(3):419-23.

Cite this article as: Kaur J, Goel B, Sehgal A, Jaswal V. Primary ovarian carcinoid: a case report. Int J Reprod Contracept Obstet Gynecol 2015;4:1546-8. 